\title{
Sport-specific reaction time after dehydration varies between sexes
}

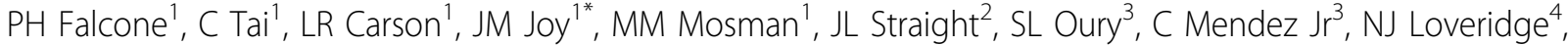 \\ JD Griffin ${ }^{5}$, MP Kim¹, JR Moon ${ }^{1,6}$ \\ From The Eleventh International Society of Sports Nutrition (ISSN) Conference and Expo \\ Clearwater Beach, FL, USA. 20-21 June 2014
}

\section{Background}

Dehydration has been shown to decrease sports performance. However, the exact cause of the decreased performance due to dehydration is still unclear. PURPOSE: To compare sport-specific reaction time values between men and women and at different quartiles after a dehydrating protocol to approximately $2 \%$ body mass loss.

\section{Methods}

Ten women and eleven men between the ages of eighteen and thirty-five volunteered to participate in the study $(27$ +/- 4yr, $78.7+/-14.8 \mathrm{~kg}, 174.0+/-7.5 \mathrm{~cm})$. Subjects reported to the lab in a fasted and normally hydrated state and completed a two-minute, multi-directional sportspecific reaction time test. Subjects then ran on a treadmill at $80 \%$ estimated max HR for 30 minutes, followed by multiple 15 minute sessions in a dry sauna at approximately 150 degrees F. After reaching a $2 \%(+/-0.4 \%)$ reduction in dry body weight subjects completed the same procedures as pre-dehydration. Reaction times were separated into quartiles (each quartile being a 30-second interval of the two minutes) and averaged to examine the data within each test. Consent to publish the results was obtained from all participants.

\section{Results}

The average total $(\mathrm{Q} 1-\mathrm{Q} 4)$ reaction time for men and women combined after dehydration (1375 +/- 210 milliseconds (ms)) was significantly higher than before dehydration $(1305+/-178 \mathrm{~ms} ; \mathrm{p}=0.0040)$. The average total reaction time for women after dehydration $(1366+/$ $400 \mathrm{~ms}$ ) was significantly higher than before dehydration $(1304+/$ - 380 ms; $\mathrm{p}=0.0048)$. However, men did not

\footnotetext{
* Correspondence: jordan@musclepharm.com

${ }^{1}$ Sports Science Institute, MusclePharm, Corp. Denver, Colorado, USA

Full list of author information is available at the end of the article
}

demonstrate a significant change in reaction time from pre $(1305+/-300 \mathrm{~ms})$ to post-dehydration $(1383+/$ $0.0516 \mathrm{~ms} ; \mathrm{p}=0.066)$. When quartiles were compared, the average reaction time for women was significantly higher in the third quartile of post-dehydration $(1404+/-245 \mathrm{~ms}$; $\mathrm{p}=0.022$ ) and the fourth quartile of post-dehydration $(1412+/-263 \mathrm{~ms} ; \mathrm{p}=0.019)$ than the first quartile of predehydration $(1272+/-198 \mathrm{~ms})$. Regarding men, the average reaction time was significantly higher in the first quartile of post-dehydration $(1427+/-220 \mathrm{~ms})$ than the first quartile of pre-dehydration $(1285+/-149 \mathrm{~ms}$; $\mathrm{p}=$ $0.040)$, the second quartile of pre-dehydration $(1285+/$ $189 \mathrm{~ms} ; \mathrm{p}=0.012$ ), the third quartile of pre-dehydration $(1338+/-200 \mathrm{~ms} ; \mathrm{p}=0.018)$, and the fourth quartile of pre-dehydration $(1312+/-236 \mathrm{~ms} ; \mathrm{p}=0.013)$. Additionally, the average reaction time was significantly higher in the second quartile of post-dehydration $(1353+/-211 \mathrm{~ms})$ than the first quartile of pre-dehydration $(1285+/-149$ $\mathrm{ms} ; \mathrm{p}=0.046$ ).

\section{Conclusions}

Dehydration appears to affect the sport-specific, total body reaction time performance of athletic men and women differently. Overall, average reaction time was significantly greater after dehydration for the combined group of men and women; however, women's average reaction time was significantly greater after dehydration, and men's reaction time trended upward, but did not reach significance. When divided into quartiles, the data suggest that women slowed down (i.e., higher reaction time) within each test and between the pre and posttests, though significance was only observed when comparing the beginning of predehydration and the end of post-dehydration. Regarding quartiles with men, the highest time point was the beginning of the post-dehydration test, and their subsequent reaction times trended lower from quartile to quartile, 
suggesting improvement. Future studies could include more subjects or a longer test in order to elucidate the discrepancy of these data. Nevertheless, this study suggests that sex differences exist regarding effects of dehydration, such that women's reaction time performance was significantly affected, whereas men's performance did not change significantly, due to a possible recovery of performance during the test.

\section{Authors' details}

${ }^{1}$ Sports Science Institute, MusclePharm, Corp. Denver, Colorado, USA.

${ }^{2} U$ niversity of Nebraska, Lincoln, Nebraska, USA. ${ }^{3}$ Metropolitan State

University of Denver, Denver, Colorado, USA. ${ }^{4}$ University of Northern

Colorado, Greeley, Colorado, USA. ${ }^{5}$ Widener University, Chester, Pennsylvania,

USA. ${ }^{6}$ United States Sports Academy, Daphne, Alabama, USA.

Published: 1 December 2014

doi:10.1186/1550-2783-11-S1-P29

Cite this article as: Falcone et al: Sport-specific reaction time after

dehydration varies between sexes. Journal of the International Society of

Sports Nutrition 2014 11(Suppl 1):P29.
Submit your next manuscript to BioMed Central and take full advantage of:

- Convenient online submission

- Thorough peer review

- No space constraints or color figure charges

- Immediate publication on acceptance

- Inclusion in PubMed, CAS, Scopus and Google Scholar

- Research which is freely available for redistribution

Submit your manuscript at www.biomedcentral.com/submit
C Biomed Central 